\title{
Tolazoline in the treatment of congenital diaphragmatic hernias
}

\author{
EDWARD SUMNER AND J DAVID FRANK
}

The Hospital for Sick Children, London

SUMMARY Four babies with congenital diaphragmatic hernias each developed a state of transitional circulation. Tolazoline was successfully used to lower the pulmonary vascular resistance and to treat this normally fatal postoperative complication.

Some children born with posterolateral (Bochdalek) diaphragmatic hernias, after an initially satisfactory postoperative recovery, develop persistent hypoxia and acidosis and then die. Such deaths, which take place despite apparently effective mechanical ventilation and attempted correction of the acidosis, are thought to be due to severe right-to-left shunting of blood (transitional circulation).

It has been shown that it is possible to reverse a transitional circulation by pulmonary vasodilating agents-for example, by tolazoline. ${ }^{1}$ Four infants, treated for congenital diaphragmatic hernias who developed this complication, survived after the use of tolazoline.

\section{Patients and methods}

The management of an infant who presents within 6 hours of birth with a congenital diaphragmatic hernia at this hospital is standard. Immediate transabdominal repair of the hernia is carried out and an ipsilateral or bilateral chest drain is inserted. Postoperatively infants are paralysed and mechanically ventilated. Direct arterial monitoring both for blood pressure and frequent blood gas analysis is essential, and is preferably carried out preductally via the right radial artery. Acidosis is corrected with $8.4 \%$ sodium bicarbonate, but if the baby develops a transitional circulation despite optimum mechanical ventilation and attempted correction of the acidosis, tolazoline is given as a bolus $(1-2 \mathrm{mg} / \mathrm{kg}$ ) over 5 minutes and is generally continued as an intravenous infusion at the same rate per hour. Blood gas analysis is carried out every 15 minutes until the arterial blood gases are stable. When these have been satisfactory for about 12 hours the tolazoline infusion is tailed off and the baby is then weaned on to continuous positive airways pressure (CPAP) and finally extubated.
Case 1. A 3-kg boy was born on 22 June 1978 by low forceps delivery at 38 weeks' gestation. He was cyanosed at birth and required endotracheal intubation. A chest $x$-ray film showed a left diaphragmatic hernia.

On admission laparotomy was performed, the left diaphragmatic hernia was repaired, and a left chest drain inserted. Postoperatively the infant required mechanical ventilation and made satisfactory progress for the first 20 hours. He then suddenly became acidotic, hypoxic, and apparently moribund. Attempted correction of the acidosis with sodium bicarbonate produced no improvement; tolazoline was given intravenously as a bolus and continued as an infusion. His condition improved during the next 2 minutes and he became 'lobster' red. This improvement was also evident in the arterial blood gas analysis (Fig. 1). At 50 hours of age the right-to-left shunting suddenly recurred despite the tolazoline infusion. A further bolus was again effective although it took 10 minutes before clinical improvement was noted. At age 74 hours the infusion stopped and there was a delay of one hour before a new drip could be set up. The shunting recurred and was again reversed with tolazoline, which was then tailed off during the next 48 hours. On 10 August the diaphragmatic hernia reoccurred and was repaired as, too, was a hiatus hernia. He was weaned on to CPAP, extubated on 20 August, and discharged home on 8 September. He remains well although he has occasional chest infections.

Case 2. A $2 \cdot 7-\mathrm{kg}$ girl was born on 7 June 1978 by caesarean section for fetal distress and a prolapsed cord. She was cyanosed at birth and required endotracheal intubation. Her chest $x$-ray film showed a right diaphragmatic hernia.

On admission she was still cyanosed and a new chest $x$-ray film showed a right pneumothorax. A 


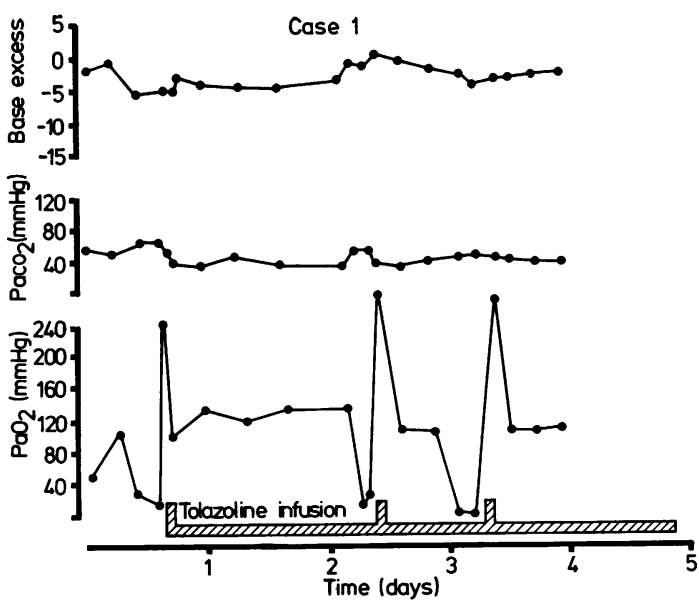

Fig. 1 (Case 1.) Blood gas analysis.

laparotomy was performed during which the hernia was repaired and a right-sided chest drain inserted. A postoperative chest $x$-ray film showed a left pneumothorax and this was drained also. Her initial progress on mechanical ventilation was satisfactory (Fig. 2).

Seventy-two hours postoperatively she became cyanosed with peripheral vasoconstriction, and a chest $x$-ray film showed a recurrence of the left pneumothorax. A needle was inserted to withdraw the air but unfortunately blood was obtained and bleeding then occurred down both chest drains and up the endotracheal tube. Resuscitation was carried out with blood and sodium bicarbonate but the baby remained cyanosed and acidotic. Tolazoline was given as a bolus; her condition rapidly improved, and she became pink and well oxygenated. She then made a slow but satisfactory recovery. She was weaned on to CPAP on 28 June, extubated on 6 July, and discharged home on 4 August. She remains well.
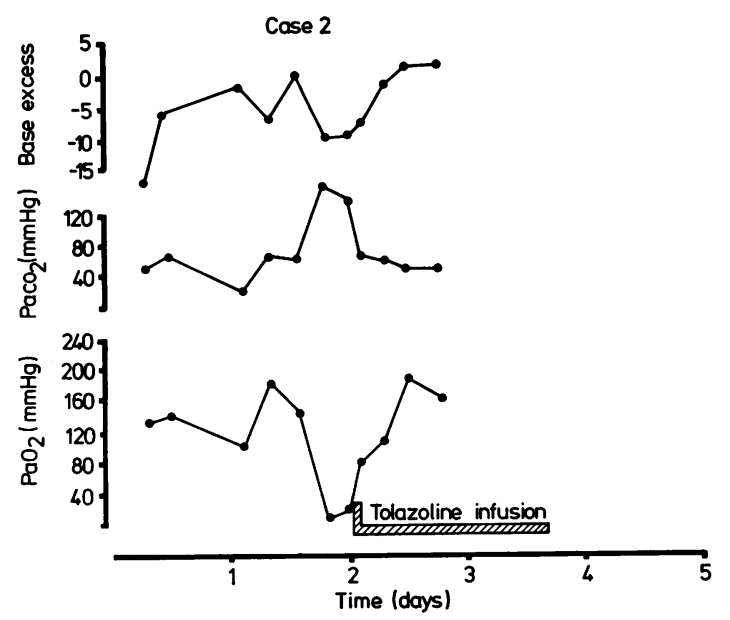

Fig. 2 (Case 2.) Blood gas analysis.

Case 3. A 3·3-kg boy was born on 4 January 1978 by a normal delivery. He was cyanosed at birth, was not intubated, but a chest $x$-ray film showed a left diaphragmatic hernia.

On admission he was intubated, the hernia was repaired at laparotomy, and a left chest drain inserted. Postoperatively he required mechanical ventilation and made an initially satisfactory recovery.

On 6 January he became cyanosed and acidotic, but a good response to sodium bicarbonate was not maintained (Table 1). Tolazoline was given as a bolus and maintained as an infusion. His clinical condition rapidly improved as the shunt reversed; the infusion was maintained until he was weaned on to CPAP; he was discharged home on 25 January. He remains well.

Case 4. A $2 \cdot 75-\mathrm{kg}$ boy was born on 28 April 1978 by a normal delivery. He was cyanosed at birth,

Table 1 (Case 3.) Arterial blood gas chart

\begin{tabular}{|c|c|c|c|c|c|c|}
\hline Date & Time & $p H$ & $\begin{array}{l}\mathrm{PCO}_{2} \\
(\mathrm{~mm} \mathrm{Hg})\end{array}$ & $\begin{array}{l}\mathrm{Po}_{2} \\
(\mathrm{~mm} H g)\end{array}$ & $\begin{array}{l}\text { Base excess } \\
(\mathrm{mmol} / \mathrm{l})\end{array}$ & Drugs \\
\hline $\begin{array}{c}\text { Janua } \\
5 \\
6\end{array}$ & $\begin{array}{l}1430 \\
0430 \\
1015 \\
2220 \\
2300\end{array}$ & $\begin{array}{l}7 \cdot 37 \\
7 \cdot 19 \\
7 \cdot 44 \\
7 \cdot 32 \\
7 \cdot 47\end{array}$ & $\begin{array}{l}36 \cdot 8 \\
59 \\
35 \\
43 \\
32 \cdot 0\end{array}$ & $\begin{array}{r}233 \\
19 \\
86 \\
38 \\
47\end{array}$ & $\begin{array}{c}-4 \cdot 1 \\
-7 \cdot 2 \\
-7 \\
-2 \cdot 5 \\
-0 \\
\text { Bolus }\end{array}$ & Bicarbonate \\
\hline 7 & $\begin{array}{l}2330 \\
0140 \\
0830\end{array}$ & $\begin{array}{l}7.38 \\
7.41 \\
7.42\end{array}$ & $\begin{array}{l}31 \cdot 6 \\
42 \\
39\end{array}$ & $\begin{array}{r}97 \\
174 \\
110\end{array}$ & $\begin{array}{l}-0.7 \\
-0.5 \\
+0.05\end{array}$ & $\left.\right|_{\substack{\downarrow \\
\text { Stopped } 48 \text { hours later }}}$ Infusion \\
\hline
\end{tabular}

Conversion: SI to traditional units- $\mathrm{Pco}_{2}$ and $\mathrm{Po}_{2}: 1 \mathrm{mmHg} \approx 0.133 \mathrm{kPa}$. 
352 Sumner and Frank

Table 2 (Case 4.) Arterial blood gas chart

\begin{tabular}{|c|c|c|c|c|c|c|}
\hline Date & Time & $p H$ & $\begin{array}{l}\mathrm{PCO}_{2} \\
(\mathrm{mmHg})\end{array}$ & $\begin{array}{l}\mathrm{Po}_{2} \\
(\mathrm{mmHg})\end{array}$ & $\begin{array}{l}\text { Base excess } \\
(\mathrm{mmol} / \mathrm{l})\end{array}$ & Drugs \\
\hline \multicolumn{7}{|l|}{ April } \\
\hline \multirow[t]{2}{*}{28} & Arrival & $7 \cdot 04$ & 82 & 96 & -11 & Bicarbonate \\
\hline & Postoperatively & $7 \cdot 17$ & 35 & 103 & -19 & Bicarbonate \\
\hline \multirow{8}{*}{$\begin{array}{l}29 \\
30\end{array}$} & 0800 & $7 \cdot 19$ & 72 & 129 & $-3 \cdot 3$ & \\
\hline & 0600 & $6 \cdot 82$ & 101 & 27 & -18 & Bicarbonate \\
\hline & 0745 & $6 \cdot 76$ & 151 & 16 & -17 & \\
\hline & & & & & Bolus & \\
\hline & 0900 & $7 \cdot 33$ & 42 & 34 & $-2 \cdot 3$ & \\
\hline & 1000 & $7 \cdot 61$ & 27 & 52 & +5 & \\
\hline & 1300 & $7 \cdot 65$ & 27 & 231 & +10 & \\
\hline & 2320 & $7 \cdot 55$ & 37 & 101 & +9 & \\
\hline
\end{tabular}

required endotracheal intubation, and a chest $x$-ray film showed a left diaphragmatic hernia.

On admission a laparotomy was performed, the hernia was repaired, and bilateral chest drains were inserted. He was mechanically ventilated postoperatively and was well until 24 hours later when he became acidotic, severely hypoxic, and hypercarbic, despite maximum ventilatory support and the use of sodium bicarbonate. Tolazoline was given as a bolus and continued as an infusion. His clinical condition rapidly improved although it took longer for his arterial blood gases to show improvement (Table 2). $\mathrm{He}$ then made an uninterrupted recovery, was weaned on to CPAP, extubated on the 12 May, and discharged home on 29 May, He remains well.

\section{Discussion}

The appearance of transitional circulation after successful repair of diaphragmatic hernia has been noted by others, ${ }^{23}$ and seems to be caused by three factors in particular:

(1). Abnormalities of lung vasculature have been demonstrated in patients with diaphragmatic hernias. ${ }^{4}$ There is a decreased total size of the pulmonary vascular bed associated with a degree of pulmonary hypoplasia and an increase in the ratio of the arterial wall thickness to the external diameter of the vessel. This increase in the media consists of smooth muscle which extends more peripherally than normal to small vessels and is consistent with arrested development at an early stage of development. Presumably these vascular changes must lead to a fixed raised pulmonary vascular resistance.

(2). All patients born with posterolateral diaphragmatic hernias have a degree of bilateral pulmonary hypoplasia which predisposes to hypoxia, hypercarbia, and acidosis.

(3). Pulmonary vasoconstriction as a response to hypoxaemia or hypercarbia is a striking feature of neonatal physiology, and this effect is increased by acidosis. $^{5}$
These three factors increase the pulmonary vascular resistance in patients with congenital diaphragmatic hernias. When the pulmonary artery pressure rises above the systemic pressure right-toleft shunting will occur through the patent ductus arteriosus, the foramen ovale, or the lung parenchyma. This increases the hypoxia and acidosis, further worsening the shunting, and producing a vicious circle which leads to a falling cardiac output. Death is inevitable unless the pulmonary vascular resistance can be reduced. It has been shown in the fetal lamb that shunting is not necessarily uni-directional and may at times be left-to-right ${ }^{6}$ through the ductus, but right-to-left through the foramen ovale.

Goetzman et al..$^{1}$ showed that in a baby without a congenital diaphragmatic hernia, a transitional circulation might be reversed with tolazoline. This drug is chemically related both to histamine and the sympathomimetic amines. It is primarily an alphaadrenergic blocker, but it also has direct nonadrenergic relaxant effects on vascular smooth muscles. It also has a direct cardiotonic effect.

Tolazoline cannot be expected to reduce a high fixed pulmonary vascular resistance or help those patients with pulmonary hypoplasia so severe as to be incompatible with life. Other authors ${ }^{4}$ have failed to demonstrate an increase in long-term survival with or without an initial response to tolazoline. We feel it is helpful to place patients with congenital diaphragmatic hernias into 5 groups.

(1) Those babies with severe cyanosis since birth who have such a severe degree of pulmonary hypoplasia that maintenance of life is only possible with the long-term use of a membrane oxygenator. ${ }^{3}$

(2) Those babies who, despite severe symptoms at birth, with pre- and postoperative respiratory support initially do well. They then revert to a state of persistent hypoxia and acidosis, and die. It is in this group, who have a potential for survival, that the use of tolazoline is indicated.

(3) Those babies, initially pink in air, who develop respiratory symptoms within the first 6 hours of life. 
They may require postoperative respiratory support for a short time but generally survive with no respiratory problems.

(4) Those babies who develop symptoms after the first 6 hours but within 24 hours of life, for whom respiratory support is rarely needed, who survive.

(5) Those children who are diagnosed later, often after a prolonged period without respiratory symptoms, who survive without any respiratory problems.

This more precise grouping will help in the analysis of the results of treatment of congenital diaphragmatic hernias.

The patients reported by previous authors who failed to respond to tolazoline probably would be in group 1 . The 4 patients presented in this paper would be in group 2 .

Thus tolazoline should be used in those babies with congenital diaphragmatic hernias who have a labile pulmonary vascular resistance and a potential for adequate arterial oxygenation. This drug should not be used however until attempts to correct a transitional circulation have been made with efficient mechanical ventilation and correction of the acidosis. Facilities must be available for arterial pressure and blood gas monitoring.

\section{Addendum}

In the latter half of 1979 and in 1980 , we used tolazoline in a further 6 infants with congenital diaphragmatic hernias suffering from transitional circulation, with the same success.
We thank the consultant surgeons at The Hospital for Sick Children, Great Ormond Street, for permission to report these patients, Mr J A S Dickson for helpful comments on the preparation of this paper, and Mrs Dorothy Duranti for her secretarial assistance.

\section{References}

1 Goetzman B W, Sunshine P, Johnson J D, et al. Neonatal hypoxia and pulmonary vasospasm: response to tolazoline. J Pediatr 1976; 89: 617-21.

2 Dibbins A W. Neonatal diaphragmatic hernia: a physiologic challenge. Am J Surg 1976; 131 : 408-10.

3 German J C, Gazzaniga A B, Amlie R, Huxtable R F, Bartlett R H. Management of pulmonary insufficiency in diaphragmatic hernia using extracorporeal circulation with a membrane oxygenator (ECMO). J Pediatr Surg 1977; 12: 905-12.

4 Levin D L. Morphological analysis of the pulmonary vascular bed in congenital left-sided diaphragmatic hernia. J Pediatr 1978; 92: 805-9.

5 Rudolph A M, Yuan S. Response of the pulmonary vasculature to hypoxia and $\mathrm{H}^{+}$ion concentration changes. $J$ Clin Invest 1966; 45: 399-411.

6 Olivet R T, Rupp W M, Telander R L, Kaye M P. Hemodynamics of congenital diaphragmatic hernia in lambs. J Pediatr Surg 1978; 13: 231-5.

7 Dibbins A W, Wiener E S. Mortality from neonatal diaphragmatic hernia. J Pediatr Surg 1974; 9: 653-62.

Correspondence to Dr E Sumner, The Hospital for Sick Children, Great Ormond Street, London WC1N 3JH.

Received 18 March 1980 